\title{
MANAJEMEN RISIKO K3 ( KESELAMATAN DAN KESEHATAN KERJA) PADA PROYEK PEMBANGUNAN RUMAH SAKIT BALI MANDARA
}

\author{
Nyoman Martha Jaya ${ }^{1}$, G.A.P. Candra Dharmayanti ${ }^{2}$ dan Dewa Ayu Retnoyasa \\ Ulupie Mesi ${ }^{3}$ \\ ${ }^{1,2,3}$ Program Studi Magister Teknik Sipil Universitas Udayana \\ Email: retnoyasa.ulupiemesi@gmail.com
}

doi: https://doi.org/10.24843/SPEKTRAN.2021.v09.i01.p04

\begin{abstract}
ABSTRAK
Proyek pembangunan Rumah Sakit Bali Mandara merupakan proyek konstruksi gedung bertingkat yang memiliki risiko K3 dalam pelaksanaan pembangunannya. Manajemen risiko K3 dilakukan dengan tujuan untuk mengetahui, menganalisis, memberikan penanganan dan menentukan kepemilikan risiko K3 yang teridentifikasi. Metode yang digunakan pada penelitian ini pada tahapan identifikasi risiko adalah brainstorming, kuesioner dan wawancara kemudian pada tahap penilaian/klasifikasi risiko dianalisis menurut AS/NZS 4360:2004, tahap penanganan diperoleh dari hasil brainstorming dengan SHE Officer dan tahap pengalokasian risiko menurut Flanagan dan Norman. Hasil identifikasi risiko pada penelitian diperoleh sebanyak 80 item risiko, 54 risiko dari penelitian terdahulu dan 26 risiko dari penelitian ini kemudian dibedakan menjadi 3 kategori/klasifikasi yaitu high risk 21 risiko (26,25\%), kategori medium risk 32 risiko (40\%), kategori low risk sebanyak 27 risiko $(33,75 \%)$. Risiko dominan diperoleh sebanyak 21 risiko seluruhnya dengan kategori high risk. Tindakan penanganan risiko $\mathrm{K} 3$ dominan diantaranya perbaikan pondasi dan melakukan sondir untuk mengetahui daya dukung tanah, melakukan perbaikan dan pengecekan kelayakan alat sebelum dipakai bekerja, penyiapan APAR dan menyediakan sistem pemadam yang baik, mempersiapkan petugas untuk segera mengantarkan pasien ke rumah sakit, segera menelepon emergency call (Rumah Sakit), memasang pagar pembatas antara site dan bangunan sekitar, memasang turap pelindung tanah, memasang jaring pengaman, menggunakan sling penjaga baja untuk memegang baja agar tidak bergerak saat dilakukan pengangkutan dengan crane, menggunakan perancah sesuai SNI dan lolos uji kelayakan, menggunakan sistem perancah yang baik, rutin cek kelayakan perancah/alat yang digunakan untuk bekerja, menggunakan formwork yang baik, memasang kornes/pagar pembatas, memakai APD lengkap. Kepemilikan risiko K3 keseluruhan dibebankan kepada pihak kontraktor yaitu petugas K3 atau SHE Officer yang memiliki tanggungjawab pelaksanaan, pengendalian dan penanganan masalah K3 pada pelaksanaan Pembangunan Rumah Sakit Bali Mandara.
\end{abstract}

Kata kunci: Risiko Keselamatan dan Kesehatan Kerja (K3), Proyek Pembangunan, Rumah Sakit Bali Mandara, Manajemen Risiko K3.

\section{OHS RISK MANAGEMENT (OCCUPATIONAL HEALTH AND SAFETY) IN THE BALI MANDARA HOSPITAL DEVELOPMENT PROJECT}

\begin{abstract}
The Bali Mandara Hospital construction project is a multi-storey building construction project that has OHS risks in the implementation of its construction. OHS risk management is carried out with the aim of knowing, analyzing, providing treatment and determining the ownership of identified OHS risks. The method used in this study at the risk identification stage was brainstorming, questionnaires and interviews, then at the risk assessment/classification stage analyzed according to AS/NZS 4360:2004, the handling stage was obtained from the results of brainstorming with the SHE Officer and the risk allocation stage according to Flanagan and Norman. The results of risk identification in the study were obtained as many as 80 risk items, 54 risks from previous studies and 26 risks from this study were then divided into 3 categories/classifications, namely high risk 21 risk $(26,25 \%)$, medium risk 32 risk category (40\%), low risk category as much as 27 risks $(33,75 \%)$. There are 21 dominant risks in the high risk category. The dominant occupational health and safety risk measures include repairing foundations and conducting sondir to determine the carrying capacity of the soil, making repairs and checking the appropriateness of tools before they are used, preparing fire extinguisher and providing a good extinguishing system, preparing officers to immediately escort patients to the hospital, calling emergency calls immediately (Hospital), installing a guardrail between the site and the surrounding buildings, installing ground protective sheeting, installing safety nets, using steel guard slings to hold the steel so that it does not
\end{abstract}


move when transported by crane, using scaffolding according to INS and passing the feasibility test, using the system good scaffolding, regularly check the appropriateness of the scaffold / tools used for work, use good formwork, install kornes/guardrails, wear complete PPE. Ownership of overall OHS risk is borne by the contractor, namely the K3 officer or SHE Officer who has the responsibility for implementing, controlling and handling OHS problems in the implementation of the Bali Mandara Hospital Development.

Keywords: Occupational Health and Safety (OHS) Risk, Development Projects, Bali Mandara Hospital, OHS Risk Management

\section{PENDAHULUAN}

Aspek Keselamatan dan Kesehatan Kerja (K3) dalam pelaksanaan pembangunan merupakan indikator penting yang mempengaruhi kemajuan pelaksanaan suatu pekerjaan konstruksi. Pemerintah mengharapkan kontraktor mampu menerapkan K3 secara mutlak dilapangan. Namun kenyataannya pelaksanaan K3 di lapangan masih belum optimal, dengan himbauan penerapan Sistem Manajemen Keselamatan Konstruksi (SMKK) oleh pemerintah masih saja terjadi kecelakaan kerja yang dapat menimbulkan kerugian-kerugian bahkan kegagalan proyek konstruksi.

Pada data Badan Penyelenggara Jaminan Sosial (BPJS) Ketenagakerjaan terdapat 123.041 kasus kecelakaan terjadi di tahun 2017 dan 173.105 kasus di tahun 2018. Kasus kecelakaan kerja tersebut menimbulkan klaim jaminan kesehatan hingga 1,2 Triliun Rupiah. Kategori kecelakaan kerja yang terjadi dari yang ringan hingga berat/fatal, dan untuk kecelakaan kerja kategori fatalitas tinggi didominasi salah satunya oleh pekerjaan dari bidang konstruksi (Widianto, 2019).

Pembangunan Rumah Sakit Bali Mandara merupakan proyek konstruksi gedung milik Pemerintah Provinsi Bali di areal Kota Denpasar dengan anggaran pemerintah yang sangat besar yaitu senilai Rp. 199.950.000.000,00 (Seratus sembilan puluh sembilan miliar sembilan ratus lima puluh juta rupiah). Pelaksanaan pembangunan gedung yang luas, tinggi bertingkat dengan basement, proses pembangunan gedung dilakukan dari awal yaitu dari pekerjaan galian tanah pondasi, banyak menggunakan alat berat, lokasi yang berada di jalur transportasi dengan kecepatan tinggi, dan risiko khusus yang mungkin tidak terdapat pada pembangunan gedung lain selain pembangunan gedung rumah sakit. Pengaturan ruangan gedung Rumah Sakit lebih spesifik dari gedung komersial karena setiap ruangan memiliki fungsi tersendiri dan memiliki bahaya kecelakaan kerja khusus seperti terjadinya luka saat pemotongan vinyl pada pekerjaan pemasangan lantai vinyl. Dilihat dari aspek transportasi dan lokasi, bahaya kecelakaan lalu lintas juga dapat terjadi saat mobilisasi alat dan bahan karena lokasi pembangunan terletak di pinggir jalan Bypass Ngurah Rai (DPU-Bali, 2015).

Berkaitan dengan hal tersebut penelitian ini dimaksudkan untuk melakukan manajemen risiko K3 pada proyek pembangunan Rumah Sakit Bali Mandara yang dilaksanakan oleh PT. PP Persero. Adapun tahapan yang akan dilakukan adalah mengidentifikasi risiko-risiko $\mathrm{K} 3$ berdasarkan sumber risiko, menganalisis dan memberikan penilaian terhadap risiko-risiko K3, merencanakan tindakan penangangan (mitigasi) yang bisa dilakukan dan mengalokasikan kepemilikan risiko K3. Cara manajemen risiko ini merupakan salah satu upaya untuk mengelola risiko (safety management).

\section{PUSTAKA}

\subsection{Pengertian $\mathrm{K} 3$}

Keselamatan dan Kesehatan Kerja merupakan kondisi-kondisi dan faktor-faktor yang berdampak atau dapat berdampak pada kesehatan dan keselamatan karyawan atau pekerja lain (termasuk pekerja kontrak dan personel kontraktor, atau orang lain) di suatu lingkungan tempat kerja. (OHSAS 18001:2007) Keselamatan dan Kesehatan Kerja (K3) merupakan suatu pemikiran dan upaya untuk menjamin keutuhan dan kesempurnaan baik jasmaniah maupun rohaniah tenaga kerja pada khususnya, dan manusia pada umumnya, hasil karya dan budaya untuk masyarakat adil dan makmur. (Mangkunegara, 2007) Keselamatan dan Kesehatan Kerja (K3) merupakan kondisi atau faktor yang mempengaruhi atau dapat mempengaruhi kesehatan dan keselamatan pekerja atau pekerja lain (termasuk pekerja sementara dan kontraktor), pengunjung, atau orang lain di tempat kerja (Ramli, 2010).

\subsection{Bahaya, Risiko dan Kecelakaan}

Bahaya (hazard) merupakan suatu keadaan yang biasanya berbentuk energi yang memiliki potensi untuk menyebabkan cedera pada manusia atau dapat menimbulkan kerusakan terhadap harta benda maupun terhadap lingkungan alam. Risiko memiliki arti kemungkinan atau potensi terjadinya sesuatu yang dapat menimbulkan kerugian. Sedangkan kecelakaan adalah kejadian yang tidak diharapkan dan (tidak direncanakan) yang dapat 
mengganggu proses operasi/produksi, merusak aset (harta benda), mencederai manusia, atau merusak lingkungan (Gunawan dkk, 2015).

\subsection{Penyakit akibat kerja}

Penyakit akibat kerja merupakan manifestasi dari kesehatan kerja, atau kondisi kesehatan dari tenaga kerja atau pekerja. (Anies, 2017) Kesehatan kerja meliputi berbagai upaya penyerasian antara pekerja dengan pekerjaan dilingkungan kerjanya baik fisik maupun psikis dalam hal cara/metode kerja, proses kerja dan kondisi kerja. Kemunculan penyakit akibat kerja ini dapat berdampak pada hasil dari pencapaian perusahaan. Mengingat pekerja merupakan penggerak dari roda pekerjaan maka dari itu kesehatan pekerja perlu diperhatikan agar tidak sampai menimbulkan penyakit akibat kerja dan berdampak pada hasil pekerjaan.

\subsection{Manajemen Risiko K3}

Manajemen Risiko K3 merupakan usaha yang dilakukan secara sistematis, terencana, terstruktur dan komperhensif dimaksudkan untuk meminimalisir adanya faktor penyebab kecelakaan kerja sehingga dapat mencegah terjadinya kecelakaan kerja yang tidak diinginkan. Adapun proses manajemen risiko yang dimaksud adalah identifikasi risiko, penilian risiko menurut AS/NZS 4360:2004, dan penanganan risiko.

1. Identifikasi Risiko K3

Proses manajemen risiko dimulai dengan identifikasi risiko, yaitu ditemukannya semua risiko kerugian dan potensi kerugian secara berhati-hati dan sistematis, tahapan ini dilakukan dengan melakukan survey (Darmawi, 2016)

2. Penilaian Risiko

Menurut Norken, dkk (2015) penilaian risiko merupakan suatu penilaian pada akibat dari risiko yang teridentifikasi, dimana besar kecilnya akibat risiko merupakan hasil dari perkalian dari frekuensi (likelihood) dengan konsekuensi (consequence) dari risiko yang telah teridentifikasi. Frekuensi (likelihood) yaitu peluang terjadinya kecelakaan dan konsekuensi (consequences) yaitu besaran kerugian pada kegiatan tertentu yang dinyatakan dalam nilai uang atau ukuran tertentu.

Pada Tabel 1. Dan Tabel 2. dibawah ini dijelaskan skala penilaian risiko terhadap frekuensi (likelihood) dan konsekuensi (consequences) menurut AS/NZS 4360:2004.

Tabel 1. Skala Penilaian Frekuensi Menurut AS/NZS 4360:2004

\begin{tabular}{|c|c|c|}
\hline Tingkat frekuensi & Deskripsi & Skala \\
\hline Almost certain (Sangat sering) & Hampir pasti terjadi disemua situasi & 5 \\
\hline Likely (Sering) & Kemungkinan terjadi disemua situasi & 4 \\
\hline Possible (Kadang-kadang) & Terjadi pada beberapa situasi & 3 \\
\hline Unlikely (Jarang) & Mungkin terjadi pada beberapa situasi & 2 \\
\hline Rare (Sangat Jarang) & Hampir tidak pernah terjadi & 1 \\
\hline
\end{tabular}

Sumber :Standards Australia/Standards New Zealand (2004)

Tabel 2. Skala Penilaian Konsekuensi Menurut AS/NZS 4360:2004

\begin{tabular}{|c|c|c|}
\hline Tingkat konsekuensi & Deskripsi & Skala \\
\hline Severe (Sangat besar) & Sebagian besar tujuan tidak dapat dicapai & 5 \\
\hline Major (Besar) & Beberapa tujuan penting tidak dapat dicapai & 4 \\
\hline Moderate (Sedang) & Beberapa tujuan terpengaruh & 3 \\
\hline Minor (Kecil) & Dampak kecil yang mudah diatasi & 2 \\
\hline Negligible (Sangat Kecil) & Dampak yang dapat diabaikan & 1 \\
\hline
\end{tabular}

Sumber :Standards Australia/Standards New Zealand (2004)

Prinsip perhitungan penilaian risiko secara kualitatif menurut AS/NZS 4360:2004 menggunakan persamaan matematika berikut :

$$
\begin{aligned}
\text { Risk } & =\text { Consequences } x \text { Likelihood } \\
\text { Dimana } ; & \text { Risk }=\text { Besarnya nilai risiko } \\
\text { Consequences dan Likelihood } & =\text { besarnya skala pada table penilaian }
\end{aligned}
$$

3. Penerimaan Risiko

Secara umum penentuan penerimaan risiko berdasarkan pengelompokkan kategori hasil penilaian risiko yang diperoleh dari perkalian antara nilai modus frekuensi (likelihood) dan konsekuensi (consequences) risiko. 
Menurut standar AS/NZS 4360:2004, penilaian tingkat penerimaan risiko diatur seperti pada Tabel 3 berikut ini.

Tabel 3. Tingkat penerimaan risiko menurut AS/NZS 4360:2004

\begin{tabular}{|c|c|c|c|c|c|}
\hline $\begin{array}{l}\text { Consecquences } \\
\text { Likelihood }\end{array}$ & $\begin{array}{c}\text { Negligible } \\
\text { (1) }\end{array}$ & $\begin{array}{l}\text { Minor } \\
\text { (2) }\end{array}$ & $\begin{array}{c}\text { Moderate } \\
\text { (3) }\end{array}$ & $\begin{array}{l}\text { Major } \\
\text { (4) }\end{array}$ & $\begin{array}{l}\text { Severe } \\
\text { (5) }\end{array}$ \\
\hline $\begin{array}{c}\text { Almost certain } \\
\text { (5) }\end{array}$ & $\begin{array}{l}\text { Medium } \\
\text { (5) }\end{array}$ & $\begin{array}{l}\text { High } \\
\text { (10) }\end{array}$ & $\begin{array}{r}\text { High } \\
(15)\end{array}$ & $\begin{array}{c}\text { Very High } \\
\text { (20) }\end{array}$ & $\begin{array}{c}\text { Very High } \\
\text { (25) }\end{array}$ \\
\hline Likely (4) & $\begin{array}{l}\text { Medium } \\
\text { (4) }\end{array}$ & $\begin{array}{c}\text { Medium } \\
\text { (8) }\end{array}$ & $\begin{array}{r}\text { High } \\
(12) \\
\end{array}$ & $\begin{array}{r}\text { High } \\
(16)\end{array}$ & $\begin{array}{l}\text { Very High } \\
\text { (20) }\end{array}$ \\
\hline Possible (3) & $\begin{array}{l}\text { Low } \\
\text { (3) }\end{array}$ & $\begin{array}{l}\text { Medium } \\
\text { (6) }\end{array}$ & $\begin{array}{l}\text { High } \\
\text { (9) }\end{array}$ & $\begin{array}{r}\text { High } \\
\text { (12) }\end{array}$ & $\begin{array}{r}\text { High } \\
\text { (15) }\end{array}$ \\
\hline Unlikely (2) & $\begin{array}{l}\text { Low } \\
\text { (2) }\end{array}$ & $\begin{array}{c}\text { Low } \\
\text { (4) }\end{array}$ & $\begin{array}{l}\text { Medium } \\
\text { (6) }\end{array}$ & $\begin{array}{l}\text { Medium } \\
\text { (8) }\end{array}$ & $\begin{array}{r}\text { High } \\
(10)\end{array}$ \\
\hline Rare (1) & $\begin{array}{l}\text { Low } \\
\text { (1) }\end{array}$ & $\begin{array}{l}\text { Low } \\
\text { (2) }\end{array}$ & $\begin{array}{l}\text { Medium } \\
\text { (3) }\end{array}$ & $\begin{array}{l}\text { Medium } \\
\text { (4) }\end{array}$ & $\begin{array}{l}\text { High } \\
\text { (5) }\end{array}$ \\
\hline
\end{tabular}

Sumber :Standards Australia/Standards New Zealand (2004)

Dari Tabel 3 di atas dapat diuraikan skala penerimaan risiko berdasarkan skala pengukuran menurut AS/NZS 4360:2004 seperti Tabel 4. dibawah ini.

Tabel 4. Skala penerimaan risiko menurut AS/NZS 4360:2004

\begin{tabular}{|l|l|}
\hline \multicolumn{1}{|c|}{ Tingkat risiko } & \multicolumn{1}{|c|}{ Deskripsi } \\
\hline Very High Risk & $\begin{array}{l}\text { Diperlukan tanggapan dari manajemen eksekutif senior, perlu } \\
\text { dilakukan rencana untuk pengambilan tindakan atau manajemen } \\
\text { pengelolaannya. }\end{array}$ \\
\hline Medium risk & $\begin{array}{l}\text { Dikelola dengan prosedur dan pengawasan dari manajemen yang } \\
\text { bertanggung jawab. }\end{array}$ \\
\hline Low risk & Dikelola dengan prosedur rutin, tidak diperlukan perlakuan spesifik \\
\hline
\end{tabular}
Sumber :Standards Australia/Standards New Zealand (2004)

Dalam AS/NZS 4360:2004 dijelaskan penentuan tingkat penerimaan risiko tidak hanya diperoleh dari kategorisasi nilai risiko (hasil perkalian konsekuensi dan frekuensi) namun penentuan kategori tingkat penerimaan risiko juga diperoleh dari bantuan data pada tabel penerimaan risiko AS/NZS 4360:2004 dengan mengkombinasi skala konsekuensi dengan skala frekuensi.

4. Penanganan risiko

Menurut Hery (2015) penanganan risiko (risk treatment) adalah sebuah proses untuk menemukan metode penanganan yang paling tepat untuk menghilangkan atau mengurangi risiko dengan alokasi biaya dan sumber daya yang paling efisien.

5. Kepemilikan risiko

Flanagan dan Norman (1993) menyatakan untuk menentukan tanggung jawab risiko, maka digunakan prinsip-prinsip sebagai berikut pihak mana yang memiliki kontrol terbaik terhadap kejadian yang menimbulkan risiko Pihak mana yang menangani apabila risiko itu muncul Pihak mana yang mengambil tanggungjawab apabila risiko tidak terkontrol dan Jika risiko diluar kontrol semua pihak, maka dianggap sebagai risiko bersama

\section{METODE}

Lokasi penelitian dilakukan di lingkungan Proyek Pembangunan Rumah Sakit Bali Mandara Jalan By Pass Ngurah Rai, Suwung Denpasar. Penelitian dimulai dari tahapan mengidentifikasi risiko K3 dengan metode brainstorming bersama SHE Officer dan berdasarkan penelitian-penelitian sejenis. Langkah selanjutnya mencari nilai frekuensi dan konsekuensi dari tiap item risiko kecelakaan yang telah teridentifikasi dengan cara membuat kuesioner dan menyebarkannya pada para responden yang telah ditentukan sebanyak 18 orang responden. Kuesioner yang digunakan diuji validitas dan reabilitasnya dengan bantuan SPSS ver.16, jika sudah valid dan reliabel dilanjutkan ke tahap penyebaran kuesioner pada para responden. Responden memberikan jawaban dalam bentuk skala likert dengan nilai 1 sampai 5 pada skala frekuensi dan konsekuensi di setiap item risiko K3. Modus yang muncul dalam skala frekuensi dan skala konsekuensi dianalisis menurut AS/NZS 4630:2004 mengenai penentuan penilaian dan tingkat penerimaan risiko kecelakaan. Dengan penilaian tersebut didapat risiko yang 
masuk pada kategori dominan yaitu high risk dan very high risk untuk ditentukan tindakan penanganan dan kepemilikan risiko K3nya melalui metode brainstorming dengan SHE Officer.

\section{HASIL DAN PEMBAHASAN}

\subsection{Identifikasi Risiko K3}

Identifikasi risiko K3 pada pelaksanaan Pembangunan Rumah Sakit Bali Mandara dilakukan dengan cara risk breakdown structure yaitu memecah risiko K3 berdasarkan 9 jenis pekerjaan yang menjadi sumber bahaya. Menyusun risiko K3 dari penelitian sebelumnya dan melakukan brainstorming dengan pihak yang terkait sehingga diperoleh sebanyak 97 risiko yang kemudian diringkas kembali menjadi 80 risiko yang akan dimasukkan kedalam kuesioner. Adapun 80 risiko yang terindentifikasi ini diperoleh dari penelitian sebelumnya sebanyak 54 risiko dan pada penelitian ini sebanyak 26 risiko.

\subsection{Uji Validitas dan Reabilitas}

Terhadap 80 pertanyaan kuesioner berdasarkan perhitungan SPSS ver.16 dapat diketahui nilai cronbach's alpha pada tabel frekuensi (likelihood) adalah 0,982 dan untuk tabel konsekuensi (consequences) adalah 0,979 sehingga berdasarkan pada hasil cronbach's alpha tersebut bahwa pertanyaan kuesioner tersebut adalah reliabel. Pengujian validitas dengan program SPSS ver.16 terhadap 80 pertanyaan kuesioner didapat nilai total correlation tiap item pertanyaan diatas 0,468 sehingga dapat dinyatakan valid.

\subsection{Distribusi Jawaban Responden}

Dari hasil sebaran kuesioner kepada 18 responden diperoleh jawaban terhadap frekuensi (likelihood) risiko berdasarkan skala penilaian AS/NZS 4630:2004. Representasi nilai responden terwakili oleh nilai modusnya seperti pada Gambar 1 berikut.

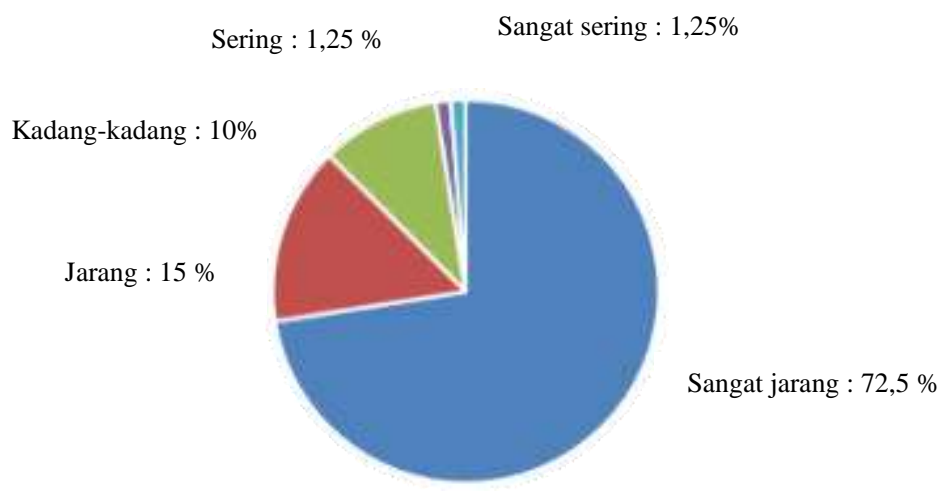

Gambar 1. Persentase Frekuensi (Likelihood) Risiko

Berdasarkan Gambar 1 diatas dapat disimpulkan bahwa frekuensi (likelihood) sangat jarang 58 risiko $(72,5 \%)$, jarang 12 risiko (15\%), kadang-kadang 8 risiko (10\%), sering 1 risiko $(1,25 \%)$ dan sangat sering 1 risiko $(1,25 \%)$. Sebagian besar responden beranggapan bahwa kejadian munculnya risiko-risiko tersebut adalah dengan skala frekuensi 1 (sangat jarang).

Gambar 2 berikut menggambarkan modus penilaian responden terhadap konsekuensi risiko (consequences).

$\begin{array}{cc} & \begin{array}{c}\text { Sangat kecil : } \\ 16,25 \%\end{array} \\ \text { Sangat besar : } & \\ 26,25 \% & \end{array}$




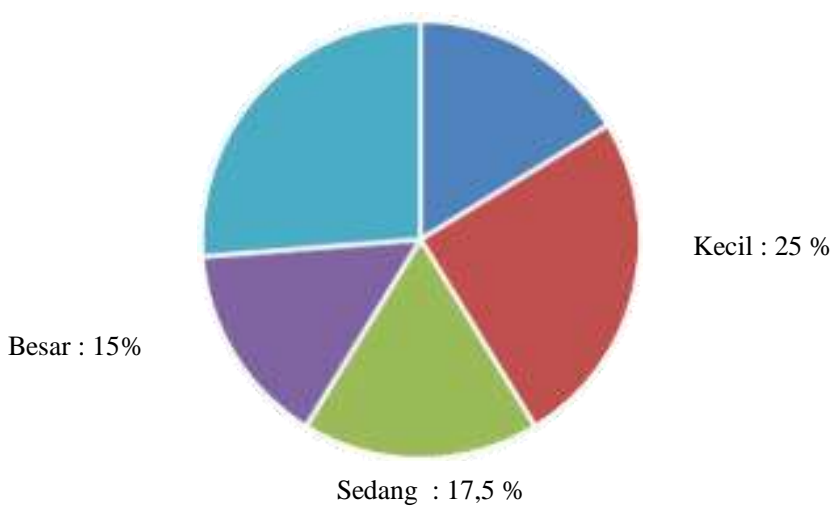

Gambar 2. Persentase Konsekuensi (Consequences) Risiko

Berdasarkan Gambar 2 diatas dapat disimpulkan bahwa konsekuensi (consequences) sangat kecil 13 risiko $(16,25 \%)$, kecil 20 risiko (25\%), sedang 14 risiko (17\%), besar 12 risiko (15\%) dan sangat besar 21 risiko $(26,25 \%)$. Sebagian besar responden beranggapan bahwa risiko yang terjadi ada dalam skala 5 (sangat besar).

Berdasarkan perhitungan penerimaan risiko sesuai dengan rumus diperoleh hasil risiko K3 teridentifikasi dibedakan menjadi 4 kategori/klasifikasi yaitu kategori very high risk sebanyak 0 risiko (0\%), kategori high risk 21 risiko (26,25\%), kategori medium risk 32 risiko (40\%), dan kategori low risk sebanyak 27 risiko (33,75\%). Data persentase tingkat penerimaan risiko tersebut diatas dapat digambarkan seperti Gambar 3 berikut ini.

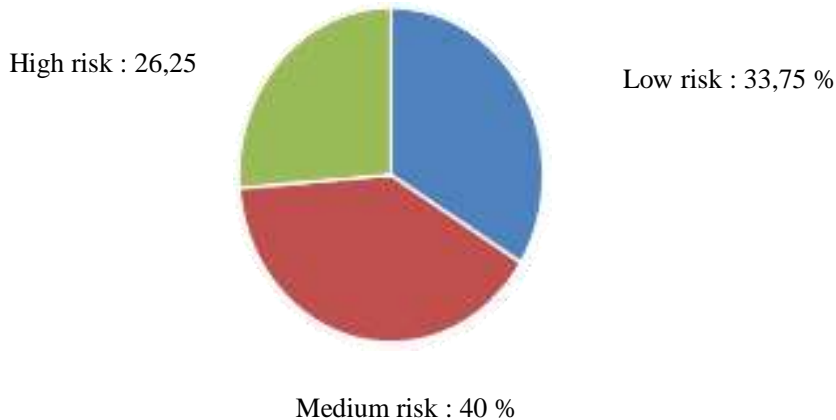

Gambar 3. Tingkat Penerimaan Risiko

Risiko dominan dapat diketahui seluruhnya berjumlah 21 risiko dari kategori high risk (26,25\%). Dalam penelitian ini tidak mendapatkan risiko yang memenuhi kategori very high risk.

\subsection{Risiko-risiko Dominan dan Penanganannya}

Risiko dominan (major risk) yang teridentifikasi direncanakan tindakan penanganan (mitigasi) yang dapat dilakukan seperti dijelaskan pada Tabel 5 berikut ini.

Tabel 5. Penanganan Risiko Kategori High Risk

\begin{tabular}{clccl}
\hline $\begin{array}{c}\text { No. } \\
\text { Risiko }\end{array}$ & Identifikasi Risiko & $\begin{array}{c}\text { Nilai } \\
\text { Risiko }\end{array}$ & $\begin{array}{c}\text { Penerimaan } \\
\text { Risiko }\end{array}$ & Penanganan Risiko \\
\hline 7 & $\begin{array}{l}\text { Crane TC miring } \\
\text { akibat pondasi miring } \\
\text { menimpa } \\
\text { pekerja/fasilitas }\end{array}$ & 5 & high risk & $\begin{array}{l}\text { Melakukan perbaikan pondasi dan melakukan } \\
\text { sondir untuk mengetahui daya dukung tanah }\end{array}$ \\
\hline 8 & $\begin{array}{l}\text { Tower crane ambruk } \\
\text { menimpa } \\
\text { pekerja/fasilitas }\end{array}$ & 5 & high risk & $\begin{array}{l}\text { Melakukan perbaikan dan pengecekan } \\
\text { kelayakan alat sebelum dipakai bekerja }\end{array}$ \\
\hline 9 & $\begin{array}{l}\text { Percikan api pada } \\
\text { mesin }\end{array}$ & 5 & high risk & $\begin{array}{l}\text { Penyiapan APAR dan menyediakan sistem } \\
\text { pemadam yang baik }\end{array}$ \\
\hline 17 & $\begin{array}{l}\text { Pekerja tertabrak alat } \\
\text { excavator }\end{array}$ & 5 & high risk & $\begin{array}{l}\text { Mempersiapkan petugas untuk segera } \\
\text { mengantarkan pasien ke rumah sakit, Segera }\end{array}$ \\
\hline
\end{tabular}




\begin{tabular}{|c|c|c|c|c|}
\hline & & & & menelepon Emergency call (Rumah Sakit) \\
\hline 18 & $\begin{array}{l}\text { Excavator menabrak } \\
\text { fasilitas sekitar }\end{array}$ & 5 & high risk & $\begin{array}{l}\text { Memasang pagar pembatas antara site dan } \\
\text { bangunan sekitar }\end{array}$ \\
\hline 19 & $\begin{array}{l}\text { Tanah } \\
\text { longsor/longsornya } \\
\text { dinding samping } \\
\end{array}$ & 5 & high risk & Memasang turap pelindung tanah \\
\hline 20 & $\begin{array}{l}\text { Pekerja jatuh } \\
\text { kedalam lubang } \\
\text { galian }\end{array}$ & 5 & high risk & $\begin{array}{l}\text { Menggunakan kornes / pagar pembatas pada } \\
\text { lubang bekas galian }\end{array}$ \\
\hline 29 & $\begin{array}{l}\text { Kerangka jatuh dan } \\
\text { menimpa } \\
\text { pekerja/fasilitas }\end{array}$ & 5 & high risk & Memasang jaring Pengaman \\
\hline 30 & $\begin{array}{l}\text { Pekerja terhantam } \\
\text { bagian baja yang } \\
\text { bergerak saat } \\
\text { diangkut dengan } \\
\text { crane menuju } \\
\text { posisinya }\end{array}$ & 5 & high risk & $\begin{array}{l}\text { Menggunakan sling penjaga baja untuk } \\
\text { memegang baja agar tidak bergerak saat } \\
\text { dilakukan pengangkuktan dengan crane }\end{array}$ \\
\hline 32 & $\begin{array}{l}\text { Robohnya cetakan } \\
\text { beton }\end{array}$ & 5 & high risk & $\begin{array}{l}\text { Menggunakan perancah sesuai SNI dan lolos } \\
\text { uji kelayakan }\end{array}$ \\
\hline 41 & $\begin{array}{l}\text { Tertimpa material } \\
\text { kayu bekisting } \\
\text { keropos saat } \\
\text { dipasang }\end{array}$ & 5 & high risk & $\begin{array}{l}\text { Menggunakan sistem perancah yang baik, } \\
\text { rutin cek kelayakan perancah/ alat yang } \\
\text { digunakan untuk bekerja }\end{array}$ \\
\hline 50 & Formwork collapse & 5 & high risk & Menggunakan formwork yang baik \\
\hline 51 & $\begin{array}{l}\text { Pekerja jatuh dari } \\
\text { ketinggian }\end{array}$ & 5 & high risk & $\begin{array}{l}\text { Memasang kornes / pagar pembatas, } \\
\text { memakai APD lengkap }\end{array}$ \\
\hline 52 & $\begin{array}{l}\text { Scafolding jatuh } \\
\text { menimpa } \\
\text { pekerja/fasiitas }\end{array}$ & 5 & high risk & Memasang jaring pengaman dan APD \\
\hline 56 & $\begin{array}{l}\text { Pekerja jatuh dari } \\
\text { ketinggian }\end{array}$ & 5 & high risk & $\begin{array}{l}\text { Memasang kornes / pagar pembatas, } \\
\text { memakai APD lengkap }\end{array}$ \\
\hline 58 & $\begin{array}{l}\text { Pekerja tertimpa } \\
\text { material peralatan } \\
\text { dan material Gypsum }\end{array}$ & 5 & high risk & Meengunakan APD \\
\hline 62 & $\begin{array}{l}\text { Pekerja jatuh dari } \\
\text { ketinggian }\end{array}$ & 5 & high risk & $\begin{array}{l}\text { Memasang kornes / pagar pembatas, } \\
\text { memakai APD lengkap }\end{array}$ \\
\hline 67 & $\begin{array}{l}\text { Tersengat listrik pada } \\
\text { mesin pengelasan } \\
\text { sambungan vinyl }\end{array}$ & 5 & high risk & $\begin{array}{l}\text { Menggunakan APD, Meningkatkan fasilitas } \\
\text { pengaman proyek }\end{array}$ \\
\hline 69 & $\begin{array}{l}\text { Pekerja terkena luka } \\
\text { bakar akibat uap } \\
\text { painting yang dapat } \\
\text { meletup dititik nyala } \\
\left.50^{\circ} \mathrm{C}\right)\end{array}$ & 5 & high risk & $\begin{array}{l}\text { Menggunakan APD, Meningkatkan fasilitas } \\
\text { pengaman proyek }\end{array}$ \\
\hline 72 & $\begin{array}{l}\text { Pekerja tertimpa } \\
\text { peralatan dari } \\
\text { ketinggian }\end{array}$ & 5 & high risk & $\begin{array}{l}\text { Menggunakan APD, Meningkatkan fasilitas } \\
\text { pengaman proyek }\end{array}$ \\
\hline 76 & $\begin{array}{l}\text { Mata pekerja terkena } \\
\text { gram besi saat } \\
\text { pemasangan pipa }\end{array}$ & 5 & high risk & $\begin{array}{l}\text { Menggunakan APD, Meningkatkan fasilitas } \\
\text { pengaman proyek }\end{array}$ \\
\hline
\end{tabular}

Sumber : Data Hasil Brainstorming dengan SHE Officer

Berdasarkan Tabel 1. risiko kategori high risk yang teridentifikasi pada pelaksanaan pembangunan Rumah Sakit Bali Mandara sebanyak 21 risiko memiliki beberapa tindakan penanganan agar risiko K3 tidak berdampak besar pada pelaksanaan proyek. 


\subsection{Kepemilikan Risiko $\mathrm{K} 3$}

Risiko yang termasuk dalam risiko dominan (major risk) pada tahap ini dialokasikan pada pihak yang bertanggung jawab atas risiko K3 tersebut adalah dari pihak kontraktor yaitu petugas K3 atau SHE Officer yang memiliki tanggungjawab pelaksanaan, pengendalian dan penanganan masalah K3 pada pelaksanaan Pembangunan Rumah Sakit Bali Mandara.

\section{KESIMPULAN \& SARAN}

\subsection{Kesimpulan}

Kesimpulan dari penelitian manajemen risiko K3 pada pembangunan Rumah Sakit Bali Mandara adalah :

1. Risiko K3 yang teridentifikasi sebanyak 80 item risiko berdasarkan 9 sumber risiko yaitu jenis pekerjaan. Dari 80 item risiko, 54 risiko diperoleh dari penelitian terdahulu yang sejenis, 26 risiko diperoleh dari penelitian ini, dan dibedakan menjadi 3 kategori/klasifikasi yaitu kategori high risk 21 risiko (26,25\%), kategori medium risk 32 risiko (40\%), kategori low risk sebanyak 27 risiko (33,75\%). Risiko dominan diperoleh sebanyak 21 risiko yang seluruhnya diperoleh dari risiko yang masuk pada kategori high risk. Tidak diperoleh risiko dengan kategori very high risk pada penelirian ini.

2. Tindakan penanganan (mitigasi) terhadap risiko K3 dominan (major risk) yang teridentifikasi dapat dilakukan dengan cara melakukan perbaikan pondasi dan melakukan sondir untuk mengetahui daya dukung tanah, melakukan perbaikan dan pengecekan kelayakan alat sebelum dipakai bekerja, penyiapan APAR dan menyediakan sistem pemadam yang baik, mempersiapkan petugas untuk segera mengantarkan pasien ke rumah sakit, segera menelepon emergency call (Rumah Sakit), memasang pagar pembatas antara site dan bangunan sekitar, memasang turap pelindung tanah, memasang jaring pengaman, menggunakan sling penjaga baja untuk memegang baja agar tidak bergerak saat dilakukan pengangkuktan dengan crane, menggunakan perancah sesuai SNI dan lolos uji kelayakan, menggunakan sistem perancah yang baik, rutin cek kelayakan perancah/ alat yang digunakan untuk bekerja, menggunakan formwork yang baik, memasang kornes / pagar pembatas, memakai APD lengkap. Kepemilikan risiko K3 secara keseluruhan dibebankan kepada pihak kontraktor yaitu petugas K3 atau SHE Officer yang memiliki tanggungjawab pelaksanaan, pengendalian dan penanganan masalah K3 pada pelaksanaan Pembangunan Rumah Sakit Bali Mandara.

\subsection{Saran}

Dengan mengacu pada simpulan diatas, maka saran-saran yang dapat disampaikan adalah sebagai berikut :

1. Pada pihak kontraktor, dalam tahap penanganan (mitigasi) risiko dan kepemilikan terhadap risiko K3 diperoleh semua risiko dominan merupakan milik dari pihak kontraktor, sehingga diharapkan penanganan yang ada pada penelitian ini dapat menjadi referensi untuk diimplementasikan pada pelaksanaan proyek guna meminimalisir adanya risiko $\mathrm{K} 3$ dan memenuhi target zero accident. Pelaksanaan proyek Pembangunan Rumah Sakit Bali Mandara meskipun tidak ditemukan risiko dengan kategori very high risk namun risiko dengan kategori high risk juga sangat mempengaruhi biaya, mutu, dan waktu pelaksanaan proyek konstruksi sehingga dalam pelaksanaannya untuk lebih diperhatikan kembali pekerjaan-pekerjaan yang memiliki risiko kategori high risk agar proses konstruksi mencapai target dengan maksimal.

2. Diharapkan hasil penelitian ini dapat menjadi pedoman untuk mengidentifikasi risiko serta melakukan tindakan penanganan (mitigasi) sehingga dapat menekan angka kecelakaan kerja pada pekerjaanpekerjaan konstruksi utamanya pada pelaksanaan konstruksi gedung. Jika diperlukan, sebaiknya dilakukan analisis risiko K3 secara kuantitatif sehingga dampak risiko dapat terukur terhadap waktu dan biaya.

\section{DAFTAR PUSTAKA}

Anies, M.Kes PKK, Prof. Dr. dr. 2017. Seri Kesehatan Umum: Penyakit Akibat Kerja. PT. Elex Media Komputindo, Jakarta

AS/NZS 4360 (2004), 3rd Edition, The Australian And New Zealand Standard on Risk Management, Broadleaf Capital International Pty Ltd, NSW Australia.

Darmawi, H. 2016. Manajemen Risiko Edisi 2. Cetakan Pertama. PT. Bumi Aksara, Jakarta

Dinas Pekerjaan Umum. 2015. Kontrak Pembangunan Rumah Sakit Bali Mandara. Dinas Pekerjaan Umum Provinsi Bali, Denpasar

Hery. 2015. Manajemen Risiko Bisnis, Enterprise Risk Management. Cetakan Pertama. PT. Grasindo, Jakarta Mangkunegara, AA A. P. 2007. Manajemen Sumber Daya Manusia. Cetakan Ketujuh. PT. Remaja Rosdakarya, Bandung

Norken, I N., Purbawijaya, I.B.N., Suputra, I. G. N. O. 2015. Pengantar Analisis Manajemen Risiko Pada Proyek Konstruksi. Cetakan Pertama. Udayana University Press, Denpasar 
OHSAS 18001 : 2007. Occupation Health and Safety Management System Requirements.

Ramli, S. 2010. Sistem Manajemen Keselamatan dan Kesehatan Kerja OHSAS 180001. PT. Dian Rakyat, Jakarta

Widianto, S. 2019. Kecelakaan Kerja 2018 Mencapai 173.105 Kasus. Jakarta : Pikiran Rakyat. Available form : URL : https://www.bpjsketenagakerjaan.go.id/berita/23322/Angka-Kecelakaan-Kerja-CenderungMeningkat,-BPJS-Ketenagakerjaan-Bayar-Santunan-Rp1,2-Triliun 